Criar Educação, Criciúma, v. 10, nำ1, jan/jul 2021.- PPGE - UNESC - ISSN 2317-2452

\title{
IMPLICAÇÕES DO SISTEMA LÍMBICO NA APRENDIZAGEM EM UMA PERSPECTIVA NEUROPSICOMOTORA
}

\author{
Elba Neri Moreira de Miranda ${ }^{1}$ \\ Paulo Vinicius Tosin da Silva ${ }^{2}$
}

\section{RESUMO}

Este artigo suscita o papel da afetividade no processo da aprendizagem á luz da abordagem neuropsicológica. Tendo em vista que a afetividade se entrelaça em processos cognitivos que ocorrem a todo o momento em que se constrói um conhecimento, entende-se que refletir sobre esta questão se torna um aspecto central no desenvolvimento humano. $\mathrm{O}$ texto tem como objetivo compreender o papel da Neuropsicologia contextualizando afetividade e aprendizagem. A pesquisa teve como referencial teórico a neuropsicologia Sócio histórica e traz a inter-relação entre a afetividade e a aprendizagem sob uma perspectiva neuropsicológica.

Palavras-chave: Sistema Límbico. Aprendizagem. Afetividade.

\section{IMPLICATIONS OF THE LIMBIC SYSTEM IN LEARNING IN A NEUROPSYCHOMOTOR PERSPECTIVE}

\begin{abstract}
This article raises the role of affectivity in the learning process in light of the neuropsychological approach. Given that affectivity intertwines in cognitive processes that occur at any moment in which knowledge is constructed, it is understood that reflecting on this question becomes a central aspect of human development. The text aims to understand the role of Neuropsychology contextualizing affectivity and learning. The research had as theoretical reference the neuropsychology Historical partner and brings the interrelationship between affectivity and learning from a neuropsychological perspective.
\end{abstract}

Keywords: Limbic system. Learning. Affectivity.

\section{INTRODUÇÃO}

Este artigo de fundamentação teórica visa uma reflexão a respeito das implicações da

\footnotetext{
${ }^{1}$ Graduação em Psicologia pela Universidade Tuiuti do Paraná, Mestrado em Distúrbios da Comunicação pela Universidade Tuiuti do Paraná. Doutoranda em Biotecnologia Aplicada à Saúde da Criança e do Adolescente nas Faculdades Pequeno Príncipe. Email: enmpsico@bol.com.br

${ }^{2}$ Graduação em Geografia pela Universidade Federal do Paraná (UFPR). Especialista em Educação Especial com Ênfase em Inclusão pela Pontifícia Universidade Católica do Paraná. Professor de Geografia e de Atendimento Educacional Especializado (AEE) na Secretaria de Estado da Educação do Paraná - SEED/PR. Email: pauloviniciustosin@gmail.com
} 
Criar Educação, Criciúma, v. 10, nำ1, jan/jul 2021.- PPGE - UNESC - ISSN 2317-2452

afetividade na aprendizagem numa perspectiva neuropsicológica. Tendo como foco esta questão, pesquisou-se sob a ótica da Neuropsicologia e da Psicologia Sócio histórica as inter-relações entre afetividade e a aprendizagem. A Psicologia Sócio Histórica (Kohl, 2001; Kohl, Souza e Rego, 2002) tem por base o homem como um ser histórico que se constrói e é construído por meio das relações que estabelece dialeticamente com o social e com o outro, sendo o afeto e a cognição elementos indissociáveis e indispensáveis no processo de aprendizagem.

A atribuição multifatorial para as causas dos problemas neuropsicológico da afetividade e suas implicações na aprendizagem, chamado de aspecto biopsicossocial, é bastante ilustrado na criança que começa na escola. Ela traz consigo, invariavelmente, as características de seu aspecto biológico, psicológico e social.

Para se estabelecer se houve ou não aprendizagem é preciso que as mudanças ocorridas sejam relativamente permanentes. Existem pelo menos sete fatores fundamentais para que tal aprendizagem se efetive, são eles: saúde física e mental, motivação, prévio domínio, maturação, inteligência, concentração ou atenção e memória. A falta de um desses fatores pode causar insucessos na aquisição de novas aprendizagens.

Portanto o presente texto tem como objetivo compreender o papel da Neuropsicologia contextualizando afetividade e aprendizagem. A Neuropsicologia é um ramo das neurociências que estuda a interação entre o comportamento e o funcionamento cerebral surgida no século XX, os estudos a respeito das inter-relações entre cérebro e mente remonta aos antigos egípcios. Este artigo está organizado em quatro seções.

As Neurociências são um conjunto de disciplinas que estudam o cérebro, a mente e o comportamento. Elas têm se difundido nas últimas décadas, especialmente a partir da fusão com a Psicologia Cognitiva. A Psicologia Cognitiva é um ramo da Ciência Cognitiva que tem por objetivo estudar a cognição sob diferentes pontos de vista, seja abstrato, humano ou mecânico (Messer, 1995). O campo de estudo da Psicologia Cognitiva abarca a investigação a respeito da memória de trabalho, da atenção, da percepção, da representação de conhecimento, do raciocínio, da criatividade e da resolução de problemas.

O desenvolvimento da Psicologia Cognitiva deu-se em conjunto com as investigações da 
Criar Educação, Criciúma, v. 10, nำ1, jan/jul 2021.- PPGE - UNESC - ISSN 2317-2452

Neuropsicologia que é um ramo da psicologia e neurologia que estuda a inter-relação entre o cérebro e o comportamento humano. A partir da década de 60 com a revolução cognitiva os psicólogos cognitivistas passaram a estudar cientificamente os processos mentais que intervém entre o estímulo e a resposta comportamental, dando impulso assim para o crescimento da Psicologia Cognitiva. Atualmente a Psicologia Cognitiva é uma das maiores escolas de Psicologia e com o avanço das pesquisas na área das Neurociências, a Psicologia Cognitiva e a Neuropsicologia fundiram-se redefinindo novas contribuições, abrindo espaço para a Neurociência Cognitiva.

\section{APRENDIZAGEM E DESENVOLVIMENTO HUMANO}

Aprendizagem é o desenvolvimento mais importante do ser humano, constitui uma resposta modificada, estável, durável, interiorizada e consolidada no cérebro do indivíduo.

A aprendizagem põe em jogo, portanto, uma relação integrada entre o indivíduo e o seu meio, isto é, coloca uma relação inteligível entre condições externas e condições internas, ou melhor, desencadeia um processo sensório-neuropsicológico entre a situação (externa) e a ação (interna). (FONSECA, 1995, P.41).

A aprendizagem, significa aquisição de uma técnica, simbólica, emotiva ou de comportamento, ou seja, mudança nas respostas de um organismo ao ambiente, que melhore tais respostas com vistas à conservação e ao desenvolvimento do próprio organismo. Este é o conceito que a psicologia moderna dá a aprendizagem. Este conceito, além disso, não é senão a generalização de uma noção de aprendizagem, considerado como forma de associação. Foi Platão (388 a.C.) o primeiro a ilustrar essa noção com sua teoria da anamnese: "Sendo toda a natureza congênita e tendo a alma aprendido tudo, nada impede de quem se lembre de uma só coisa - que é o que se chama aprender - encontre em si mesmo todo o resto, se tiver constância e não desistir da procura, porque procurar e aprender nada mais são do que reminiscência". O aprendizado é segundo Platão, à associação das coisas entre si, pela qual a alma pode, após haver captado uma coisa, captar também a outra que a esta se encontra vinculada.

Para compreender, o processo de aprendizagem faz-se necessário uma abordagem teórica sobre o desenvolvimento cognitivo no processo da aprendizagem. Descrito por Jean Piaget que foi um psicólogo suíço, falecido em 1980, cujos trabalhos são mundialmente conhecidos e, por mais de 
Criar Educação, Criciúma, v. 10, nำ1, jan/jul 2021.- PPGE - UNESC - ISSN 2317-2452

quarenta anos ele realizou pesquisas com crianças visando não somente conhecer melhor a infância para aperfeiçoar os métodos educacionais, mas também para compreender o homem.

Usando a observação direta, sistemática e cuidadosa de crianças (incluindo seus três filhos), Piaget chegou a uma teoria que revolucionou nossa compreensão do desenvolvimento intelectual. Esta teoria o desenvolvimento mental do ser humano no campo do pensamento, da linguagem e da afetividade.

Piaget propôs, antes de qualquer coisa, que o desenvolvimento cognitivo se realiza em estágios. Isso significa que a natureza e a caracterização da inteligência mudam significativamente com o passar do tempo. Em linhas gerais, Piaget esquematiza o desenvolvimento intelectual nos estágios seguintes: sensório motor (de zero à dois anos); pré-operacional(de dois à seis anos); de operações concretas (de sete à onze anos); de operações formais (doze anos em diante). As idades atribuídas ao aparecimento dos estágios não são rígidas, havendo grande variação individual.

A análise da relação entre desenvolvimento e aprendizagem, antes de ser de cunho psicológico, são de natureza essencialmente epistemológica. Ela está vinculada, à relação sujeito/objeto do conhecimento. É sabido que todo conhecimento implica necessariamente, uma relação entre dois polos, isto é, entre sujeito que busca conhecer e o objeto a ser conhecido.

Como se constrói o conhecimento? Nas sistematizações teóricas de Piaget, conhecer significa organizar, estruturar e explicar o real a partir das experiências vividas. Conhecer é modificar, transformar o objeto, é compreender o mecanismo de sua transformação, e consequentemente, o caminho pelo qual o objeto é construído. O conhecimento é sempre produto da ação do sujeito sobre o objeto. Orientado pelos princípios da biologia, Piaget viu na coordenação funcional da ação adaptativa, a origem de todo o conhecimento.

O ser humano, segundo Piaget, nasce com a possibilidade de, através da interação com o meio ambiente, construir seus esquemas de ação integrando-os em sistemas cada vez mais abrangentes. Piaget distingue a aprendizagem de maturação, destacando que a maturação é baseada exclusivamente em processos fisiológicos. Distinguem também aprendizagem de conhecimento, pois para ele, o conhecimento se define pela soma de coordenações, que tendo passado por um lento processo de desenvolvimento, encontram-se disponíveis para o organismo em determinado estágio. Já o conceito de 
Criar Educação, Criciúma, v. 10, nำ1, jan/jul 2021.- PPGE - UNESC - ISSN 2317-2452

aprendizagem em sentido estrito, está diretamente vinculado às aquisições que decorrem fundamentalmente das contribuições proveniente do meio externo. (PIAGET, 1970; PIAGET, 2003)

Toda a aprendizagem pressupõe a utilização de mecanismos não aprendidos, ou seja, pressupõe a utilização de um sistema lógico (ou pré-lógico) capaz de organizar as novas informações (terreno da equilibração).

O sistema de equilibração coloca-se como elo entre o desenvolvimento e a aprendizagem, combinando os fatores de ação externos com os de organização interna, inerentes à estrutura cognitiva. Quando Piaget fala em aprendizagem no sentido geral, ele está se reportando ao processo de desenvolvimento.

$\mathrm{Na}$ verdade, a aprendizagem propriamente dita equivale tão somente à aquisição de novos conhecimentos. Como todo o conteúdo só pode ser atingido pela mediação de uma forma, não é difícil perceber que, na concepção de Piaget, o processo de aprendizagem é subjugado ao processo de desenvolvimento, sendo por este condicionado.

As ações humanas são ações sociais, cognitivas, discursivas e pragmáticas. Incluídas estão as formas de agir sobre o mundo: com o corpo, com os movimentos desse corpo, com olhar, com as expressões de afeto, amor e ódio, com as palavras, com os silêncios...

\section{O FUNCIONAMENTO DO CÉREBRO NO PROCESSO DE APRENDIZAGEM}

Em decorrência dos avanços das pesquisas neurológicas e estudos realizados por neurocientistas; é curioso conhecer o funcionamento do cérebro e sua plasticidade; que mesmo sofrendo traumatismos, tem condições de reconstituir-se na busca da construção do conhecimento humano.

De momento, e na base de investigações em vários campos, a aprendizagem envolve complexos processos neurológicos, nomeadamente reações químicas, atividades bioelétricas, arranjos moleculares nas células nervosas e glias, eficiência sináptica, redes interneuronais, metabolismo proteico, mielinização, ramificações dendríticas, etc. Em outra dimensão, a aprendizagem compreende funções de descodificação, transdução, armazenamento, combinação, codificação, reforço, etc., que colocam a imediatividade da experiência social. (FONSECA, 1995, P. 41). 
Criar Educação, Criciúma, v. 10, nำ1, jan/jul 2021.- PPGE - UNESC - ISSN 2317-2452

Segundo Fonseca (1995), a aprendizagem satisfatória ocorrerá quando determinadas condições de integridade estão presentes. Estas condições incluem funções do sistema nervoso (periférico e central) e também funções psicodinâmicas e sócio dinâmicas. Numa situação ideal, a aprendizagem envolve um conjunto de sistemas psiconeurológicos subdivididos em três componentes de processamento: processamento sensorial, processamento cognitivo e processamento de conteúdo.

Os sistemas de processamento sensorial evocam as relações entre os sistemas neurossensoriais visuais, auditivos e tátil-sinestésicos, que se relacionam e se integram em áreas específicas no cérebro, por níveis diferenciados: alguns intrasensoriais, outros intersensoriais e integrativos.

Os sistemas de processamento cognitivo põem em destaque a hierarquia da experiência diferenciada em quatro níveis: 1. Percepção: Processo de conversão, seleção e interpretação das sensações; 2. Imagem: Processo que diferencia a percepção da retenção, permitindo a relação com a sensação depois de esta ter sido interrompida; 3. Simbolização: Processo de reexperimentação de equivalência significativa e de representação interior da experiência e; 4; Conceitualização: Processo de classificação e de categorização da informação através de sistemas de agrupamento de atributos, que permitem a formação de conceitos e o acesso à abstração e ao pensamento formal.

Por último, os sistemas de processamento de conteúdo colocam em jogo a especialização hemisférica, condição antropológica básica da evolução, diferenciando as funções do hemisfério direito das do hemisfério esquerdo.

O hemisfério direito, responsável pelos conteúdos não-verbais, realiza preferencialmente as seguintes funções: 1. Funções visuais: localização de pontos em duas dimensões, enumeração de pontos e formas, reconhecimento de faces e de figuras sem significado; 2. Funções manuais (tátilsinestésicas): reconhecimento de revelo, a exemplo da escrita Braile e reconhecimento de estruturas; 3. Funções auditivas: sons da vida cotidiana e padrões melódicos.

Em compensação, o hemisfério esquerdo tem sido considerado responsável pelos conteúdos verbais. Neste sentido, Kimura (1973), preferencialmente, as seguintes funções: 1. Funções visuais: Reconhecimento de letras e palavras; 2. Funções manuais (tátil-sinestésicas): Movimentos complexos, a exemplo da fala e funções auditivas, tais como o reconhecimento de palavras e de sílabas. 
Criar Educação, Criciúma, v. 10, nำ1, jan/jul 2021.- PPGE - UNESC - ISSN 2317-2452

Conforme Fonseca (1995), é evidente que as funções são, por um lado, intra-hemisféricas, mas, por outro, inter-hemisféricas e integrativas. Em todos os produtos do comportamento humano, fala, movimento, etc., verifica-se o corolário das cofunções hemisféricas, que, no fundo, caracterizam todas as realizações práticas e simbólicas especificamente humanas, como sejam as aquisições da leitura e da escrita.

Em 1984, Luria referiu em sua obra os processos mentais de atenção, percepção e memória relacionando-os ao processo de aprendizagem e à compreensão das suas dificuldades no contexto educacional. Tais processos mentais são tidos como as bases neuropsicológicas da aprendizagem, pois permite a realização de funções como: seleção de elementos para atividade mental, manutenção do organismo sob estado de alerta e vigilância, distinção de aspectos essenciais de objetos, comparação de objetos, formação e comparação de hipóteses e a fixação de informação, considerando a quantidade e a duração de seu armazenamento.

Estes processos mentais envolvem o funcionamento coordenado, em série e em paralelo, de diversas zonas cerebrais, tendo como aspecto mediador, a linguagem. A aprendizagem é considerada uma função neural complexa, pois envolve o funcionamento de diversos processos mentais que correspondem à ativação e inibição de diversas áreas cerebrais concomitantemente.

A linguagem, entendida como trabalho constitutivo exclui, de modo radical, a possibilidade de que o desenvolvimento cognitivo possa acontecer desvinculado da linguagem do outro e dos signos; impossível pensar desenvolvimento cognitivo fora da cultura e da linguagem; impossível pensar isso tudo sem o papel fundante dos processos de significação. Processos de significação que se criam entre as pessoas, no meio social. Cada objeto, cada ação, cada palavra, cada aprendizagem adquire, segundo Bakhtin “Significação Interindividual”. (FREITAS, 2000)

Significa interindividual, ou seja, o que faz da palavra uma palavra é a sua significação. O que faz da atividade psíquica uma atividade psíquica é, da mesma forma, sua significação. (BAKHTIN, 1992, P. 49).

Piaget enfatiza a importância da estimulação ambiental como essencial ao desenvolvimento cognitivo e a aprendizagem. Por isso os ambientes enriquecidos e estimulados com recursos materiais, prática de exercícios físicos e uma boa nutrição influenciaram no desenvolvimento da memória e na 
Criar Educação, Criciúma, v. 10, nำ1, jan/jul 2021.- PPGE - UNESC - ISSN 2317-2452

aprendizagem. Pesquisas médicas atestam que o desenvolvimento do cérebro ocorre mais rápido nos primeiros anos de vida da criança. O desenvolvimento sadio do cérebro atua diretamente sobre a capacidade cognitiva.

O lado direito do cérebro é responsável pela imaginação criativa, a serenidade, a capacidade de síntese, a facilidade de memorizar. As pessoas que utilizam mais esse lado do cérebro possuem habilidades para analisar esquemas e técnicas em oratórias. Para que a memória funcione adequadamente no processo de informação; faz-se necessário a busca da integração entre os dois hemisférios, equilibrando o uso de nossas potencialidades.

Torna-se necessário estimular as áreas do cérebro objetivando auxiliar os neurônios a desenvolverem novas conexões, educar as crianças desde a mais tenra idade em um ambiente enriquecedor, estimulando a linguagem falada, cantada, escrita, estruturado com afetividade e diversificando positivamente as sensações, com a presença de cor, de música, de interações sociais, e de jogos visando o desenvolvimento de suas capacidades cognitivas e memórias futuras, favorecendo assim o seu processo de aprendizagem.

Nesse sentido observa-se que devido às inúmeras pesquisas desenvolvidas sobre o cérebro no processo de aprendizagem, verifica-se que cada indivíduo possui diferentes potenciais de inteligência. E que ela não é fixa, já que todo ser humano possui habilidade para expandir e aumentar sua própria aprendizagem.

\section{AFETIVIDADE COGNIÇÃO}

Os afetos segundo Bock (1999), estão sempre presentes na vida psíquica, ocorrem associados aos pensamentos, as fantasias e sonhos expressando-se diferentemente na conduta de cada indivíduo. Os afetos nos ajudam a avaliar situações, servem de critério de valoração positiva e negativa e participam ativamente na percepção que temos das situações vividas e no planejamento de nossas ações. Além disso, a afetividade está ligada à consciência, o que nos permite dizer ao outro o que 
Criar Educação, Criciúma, v. 10, nº1, jan/jul 2021.- PPGE - UNESC - ISSN 2317-2452

sentimos através da linguagem e das emoções. De acordo com Wallon (1986, p. 64)

As emoções podem ser consideradas, sem dúvida, como a origem da consciência, visto que exprimem e fixam para o próprio sujeito, através do jogo de atitudes determinadas, certas disposições específicas de sua sensibilidade. Porém, elas só serão o ponto de partida da consciência pessoal do sujeito por intermédio do grupo no qual elas começam por fundi-lo e do qual ele receberá as fórmulas diferenciadas de ação e os instrumentos intelectuais, sem os quais lhe seria impossível efetuar as distinções e as classificações necessárias ao conhecimento das coisas e de si mesmo.

A afetividade não se constitui apenas de sentimentos que abrangem fatores positivos, mas também fatores negativos, permeados pela rejeição, pelo ódio, pela indiferença presentes no cotidiano de todo e qualquer ser humano. O desenvolvimento da afetividade ocorre na vida do ser humano desde seus primeiros momentos de vida, a medida que se estabelece um contanto com o outro e com o meio externo. A partir do estabelecimento das relações, têm-se as primeiras percepções, sensações e emoções com relação ao que se vivencia, e é internalizado de forma bastante singular a cada indivíduo, se constituindo como parte da subjetividade, e da identidade deste indivíduo A emoção e a cognição por estarem ligadas aos sentimentos contribuem para a construção e para ressignificação que cada sujeito dará de maneira muito particular as relações por ele estabelecidas com o social e com o outro.

A palavra afeto vem do latim affectu (afetar, tocar) e constitui o elemento básico da afetividade, conjunto de fenômenos psíquicos que se manifestam sob a forma de emoções, sentimentos e paixões, acompanhados sempre da impressão de dor ou prazer, de satisfação ou insatisfação, de agrado ou desagrado, de alegria ou tristeza. (CODO, 2002, p. 51).

Ao falar do campo afetivo e de sua dimensão emocional, é importante diferenciar e esclarecer os conceitos de emoção e sentimento, uma vez que em nosso cotidiano esses termos são empregados de forma muito generalizada para explicar as complexas dimensões do afeto. Para Bock (1999), as emoções são expressões do afeto acompanhadas de reações intensas e breves do organismo, como resposta a um acontecimento inesperado, provocando reações orgânicas como o tremor, o riso, o choro que revelam vivências ou estados emocionais, que não podem ser contidas. Por sua vez, o sentimento é um estado mais tênue e durável, podendo expressar os afetos básicos como o amor e o ódio, são mais 
Criar Educação, Criciúma, v. 10, nำ1, jan/jul 2021.- PPGE - UNESC - ISSN 2317-2452

duradouros e vêm acompanhados de reações orgânicas bem menos intensas.

Conforme Lane e Sawaia (1995, p. 58), “os sentimentos significam que uma pessoa está implicada com algo ou alguém e este fato pode se constituir desde emoções simples até os sentimentos mais complexos que caracterizam a própria personalidade do indivíduo".

A emoção e o sentimento são a expressão da afetividade, manifestando-se através de reações orgânicas, como o choro, o riso e a palpitação, essas manifestações podem ser apenas reflexos instintivos para a adaptação de uma situação, como também podem caracterizar os aspectos mais profundos da subjetividade. Tendo a emoção relação com a formação do caráter e com os processos da formação da estrutura psicológica da personalidade, Vygotsky acredita que:

A emoção por seu significado emocional está ligada não só à situação instintiva na qual se manifesta, como se observa, em particular nos animais, mas é um dos elementos que formam o caráter e demonstrou que as ideais gerais do homem sobre a vida, a estrutura de seu caráter, por um lado, se refletem em uma determinada parte da vida emotiva, por outro, são determinadas por essas emoções. (LANE E SAWAIA, 1995, p. 121)

A partir dessa ideia Vygotsky vê a necessidade de se tentar compreender a transição entre as emoções primitivas da vida e as experiências emocionais superiores. Segundo Arantes (2003, p. 20), "Vygotsky faz uma distinção entre emoções primitivas originais como a alegria, o medo e a raiva e as emoções "superiores" complexas, tais como o despeito e a melancolia". As emoções primitivas são claras e de origem instintiva biológica, no entanto no decorrer do desenvolvimento essas emoções foram se transformando, afastando-se da sua concepção biológica e se constituindo enquanto fenômenos culturais e históricos.

\section{O SISTEMA LÍMBICO E A AFETIVIDADE}

A espécie humana é a espécie que apresenta e manifesta a maior gama de emoções e sentimentos, isto devido à evolução do sistema límbico. A evolução do sistema límbico teve início com os primeiros mamíferos. O termo Sistema Límbico foi introduzido por Paul Mc Lean no ano de 1952, tendo sua importância destacada por Bear (2006) que assinalou a permissividade desse sistema para 
Criar Educação, Criciúma, v. 10, nำ1, jan/jul 2021.- PPGE - UNESC - ISSN 2317-2452

que os animais experimentassem e exprimissem as emoções, além da emancipação do comportamento estereotipado variante em função do tronco encefálico.

O sistema límbico ocupa um papel central no campo da afetividade, sendo ele responsável pelas emoções. Está localizado na superfície medial do cérebro e é constituído por neurônios que formam uma massa cinzenta denominada de lobo límbico. Conforme Bear (2006 p. 584) “ o lobo límbico consiste do córtex ao redor do corpo caloso, principalmente no giro cingulado, e o córtex na superfície medial do lobo temporal, incluindo o hipocampo."

O sistema límbico é composto por diversas estruturas importantes: amígdala, hipocampo, tálamo, hipotálamo, giro cingulado, tronco cerebral, área tegmental ventral, septo e área pré-frontal. Os conjuntos de estruturas que compõem o sistema límbico se encontram envolvidas em vários aspectos com a emoção como: o armazenamento de lembranças emocionais e o reconhecimento de manifestações faciais de emoção.

A amigdala cerebral é uma das estruturas mais importantes do sistema límbico e tem sido apontada como a estrutura límbica fundamental envolvida na neurobiologia da emoção. A amigdala é uma estrutura muito importante quando falamos de emoções e de afetividade, uma vez que esta é responsável por atribuir significado emocional as emoções. A amigdala cerebral recebe informações vindas do tálamo e do hipotálamo tálamo é a estrutura que atua na recepção das informações sensoriais vindas do meio externo. O hipotálamo está envolvido no controle da sexualidade e do apetite e atua como receptor das informações corporais.

O hipocampo é uma das estruturas que compõem o sistema límbico e está envolvido com a memória. O hipocampo e a amidala atuam juntos no armazenamento de lembranças, a amidala dá a conotação emocional à lembrança e o hipocampo dá os detalhes e o contexto não emocional.

\section{AFETIVIDADE E COGNIÇÃO NA CONSTITUIÇÃO DO PSIQUISMO: CONTRIBUIÇÕES DA NEUROPSICOLOGIA E DA PSICOLOGIA SÓCIO HISTÓRICA}

O indivíduo é construído ao longo de sua vida a partir de sua intervenção no meio (sua atividade instrumental) e da relação com os outros.

Partindo da premissa que o homem é um ser social, que constrói e é construído pelo meio 
Criar Educação, Criciúma, v. 10, nำ1, jan/jul 2021.- PPGE - UNESC - ISSN 2317-2452

através de relações dialéticas num movimento constante de transformação, entende-se que o homem se constitui através do conhecimento que constrói a partir das relações dialéticas e para isso utiliza suas funções psíquicas superiores, produto da atividade cerebral que parte da unidade dos processos psíquicos e fisiológicos que se desenvolveram ao longo da sua evolução dentro de um processo sócio histórico.

Na Psicologia Sócio Histórica, a análise do psiquismo, é determinada por bases materiais e concretas através das quais se constitui uma sociedade. A expressão psíquica do homem suplanta seu arcabouço biológico e passa a constituir a subjetividade. Luria et al. (1987), ao falar sobre o psiquismo humano afirma que o objeto da psicologia "é o reflexo do mundo externo no mundo interno - a interação do homem com a realidade" (p. 76). Assim compreende-se que o psiquismo humano é constituído a partir da ação do homem em resposta a seu meio. Tendo como marco diferencial que suas ações não são puramente motivadas por aspectos biológicos como acontece com os animais.

Pode-se dizer então que a atividade humana caracteriza-se pelo trabalho social e este, considerando as divisões de funções e o uso de ferramentas que mediam sua produção, dá origem a novas formas de comportamentos independentes dos comportamentos gerados por motivos biológicos elementares. Além do trabalho social e da utilização de ferramentas, o homem tem como característica que o diferencia dos demais animais, o uso da linguagem.

Conclui-se que o homem tem duas grandes diferenças que o distingue dos demais animais: uma é a capacidade de trabalhar e produzir, ter ações que geram através de um comportamento uma produção mediada pelo uso de ferramentas, e a outra é a linguagem. Bock (2001, p. 76) fala que "o sistema de códigos teve importância decisiva para o desenvolvimento posterior da atividade consciente do homem".

Conforme Lúria (1985) existem três peculiaridades fundamentais que distingue a atividade consciente do homem, do comportamento individualmente variável do animal: $1^{\mathrm{O}}$ - a atividade humana não se relaciona forçosamente com as motivações biológicas; $2^{\circ}$ - a atividade consciente não está absoluta ou forçosamente determinada por impressões vivas recebidas do meio ou por contingências da experiência individual direta; $3^{0}$ - o comportamento do homem não tem como fonte somente os 
Criar Educação, Criciúma, v. 10, nำ1, jan/jul 2021.- PPGE - UNESC - ISSN 2317-2452

programas hereditários e os resultados de sua experiência individual, uma vez que o homem também produz conhecimento e arte através da assimilação da experiência acumulada no processo histórico social e transmitida pela aprendizagem. Com base no arcabouço de Leontiev, (BOCK 2001, p.79) diz que a:

Hominização resultou da passagem à vida numa sociedade organizada na base do trabalho; essa passagem modificou sua natureza e marcou o início de um desenvolvimento que diferentemente do desenvolvimento dos animais, estava e está submetido às leis sócio históricas.

O homem através de sua evolução ultrapassou a mera adaptação à natureza, se modificou e evoluiu em função do desenvolvimento de suas necessidades. Ele adquiriu capacidade para desenvolver atividades criadoras e produtivas. A produção é um processo social que se desenvolve por leis próprias. Portanto, o homem sócio histórico não nasce pronto, "cada indivíduo aprende a ser homem. O que a natureza lhe dá quando nasce não lhe basta para viver em sociedade” (BOCK, 2001.p.80). Existe aí um processo de apropriação do mundo para a constituição de uma consciência, que consiste na formação das faculdades específicas do homem: aquisição de instrumento e a linguagem. Como cada um desses aspectos influi na constituição da subjetividade, facilitando assim a compreensão se forem delineados cada um em suas especificidades.

O instrumento constrói a função de acumulação (retenção), que será a base para a construção da cultura. Permite a possibilidade de operações. Originalmente, esse instrumento, foi o instrumento de trabalho [...] fazia parte da consciência do grupo que operava e construía esse instrumento. (FURTADO 2001, P.80).

Isso exigia uma capacidade de antecipação de uma tarefa realizada e uma atividade criadora.

Por sua vez a linguagem é o processo de apropriação de operações de palavras "que são fixadas historicamente nas suas significações" (FURTADO 2001, p. 80). Esse processo de apropriação cria no homem novas aptidões, novas funções psíquicas. A linguagem se constitui como um fator essencial para a formação da consciência. "Permite a retenção na memória, que por sua vez, permite a designação de objetos sem sua presença” (BOCK 2001, p. 78), isso faz com que a percepção humana seja dobrada criando um mundo de imagens internas. Para Bock $(2001$, p.78) a linguagem "permite o processo de abstração e generalização. A palavra permite o processo de análise e classificação, o que 
Criar Educação, Criciúma, v. 10, nำ1, jan/jul 2021.- PPGE - UNESC - ISSN 2317-2452

possibilita o trânsito do reflexo sensorial para a construção do mundo racional através do pensamento". Ela permite ao homem desligar-se da experiência direta e garante o nascimento de processos mais elaborados, inexistentes nos animais. A linguagem é um dos principais instrumentos para que ocorra o processo de mediação das relações sociais pela qual o homem se humaniza, se individualiza, apreende e materializa as significações construídas num processo sócio histórico. Desta forma a linguagem se configura como "um lugar de constituição e expressão dos modos de vida culturalmente elaborados" (Kohl, Souza e Rego, 2002, p. 163) e

\begin{abstract}
atua como um instrumento de comunicação entre o homem e o social, onde a relação do homem com o mundo tem sempre por intermediário a relação do homem com outros seres humanos sua atividade está ligada a comunicação. A comunicação é a condição necessária específica do desenvolvimento do homem na sociedade. Desde os primórdios, foi a vida em grupo e a capacidade de comunicação entre os membros desse grupo o fenômeno responsável pela retenção coletiva do conhecimento. (FURTADO 2001, P. 81).
\end{abstract}

Portanto com a utilização de instrumentos e com o desenvolvimento da linguagem como mediadora entre os processos externos e internos, no decorrer da sua evolução histórica, o homem foi se modificando e transformando suas relações, se desenvolvendo em sociedades de classes e produzindo a cultura. Assim, a consciência é entendida como uma construção social, e deve ser vista como um sistema integrado, num processo de construção permanente no qual ocorre a interação entre o homem e a sociedade (externo) e o homem e seus pensamentos, ações e sentimentos (interno), constituindo uma consciência que não existe nos animais. Desta forma, pode-se dizer que a consciência não tem origem no próprio indivíduo, ocorrendo por meio de uma construção social, a partir da relação do homem com a realidade - meio externo - e pela internalização dos processos psíquicos. Esse processo de constituição da consciência não se faz pela internalização em si, mas através de uma atividade significada, dado que

A invenção e o uso de signos como meios auxiliares para solucionar um dado problema psicológico (lembrar comparar coisas, escolher etc.) é análoga a invenção e uso de instrumentos, só que agora no campo psicológico. O signo age como um instrumento da atividade psicológica de maneira análoga ao papel de um instrumento no trabalho. Mas essa analogia, como qualquer outra não implica uma identidade desses conceitos similares. VYGOTSKI (1991, P. 59-60) 
Criar Educação, Criciúma, v. 10, nำ1, jan/jul 2021.- PPGE - UNESC - ISSN 2317-2452

Portanto, o signo assim como o instrumento, tem função mediadora, a diferença está em que o signo é orientado internamente, e está no campo subjetivo, enquanto que o instrumento é orientado externamente pela atividade que está no campo da objetividade. Conforme Bock (2001, p.84), "para Vygotsky, a combinação entre signo e instrumento na atividade psicológica, gera a função psicológica superior (ou comportamento superior como correlato da função), que ultrapassa o organicamente demarcado". Desta forma o signo não é compreendido apenas como uma ferramenta que transforma o mundo externo, ele é orientado para regular as ações sobre o psiquismo das pessoas, é um meio de atividade interna que influencia psicologicamente a conduta do outro e a sua própria conduta, através do sentido que dá ao seu pensamento, através do uso da linguagem.

Ter consciência de si e do outro, é uma característica que faz com que cada ser humano construa, através de sua conduta, sua própria identidade, e por estar em relação com o seu meio cria uma identidade cultural. A consciência compreende a reflexão do indivíduo sobre suas ações levandose em conta sua possibilidade subjetiva de produção e de transformação, através da relação com a realidade social. A subjetividade se constitui das relações que o homem estabelece com o meio e por meio da interação entre as funções mentais, que adquirem significados através da linguagem. A linguagem é então o meio pelo qual o homem estabelece conceitos e organiza o real, ou seja, dá significado, através do qual compreende o mundo, se compreende e relaciona-se com ele. Como é apontado por Vygotsky (1996) a forma de pensar, que junto com o sistema de conceito (linguagem) nos foi imposta pelo meio que nos rodeia, inclui também nossos sentimentos.

A elaboração do pensamento inclui não somente componentes cognitivos, intelectuais, mas também as emoções. A palavra é um mediador do conhecimento e possui além do significado, referente ao sistema de relações objetivas, também o sentido referente ao significado da palavra para cada pessoa por meio das experiências individuais, pode-se afirmar que é no sentido "que residem às vivências afetivas”. (KOHL, SOUZA E REGO, 2002)

A atividade consciente que se dá por processos de internalização, que compreendem as funções psicológicas e o processo de formação da subjetividade, não ocorre apenas nas dimensões cognitivas e intelectuais, mas também na dimensão emocional. O desenvolvimento afetivo, na visão sócio histórica constitui-se a partir das relações entre as funções psicológicas relacionadas à cognição e as funções 
Criar Educação, Criciúma, v. 10, nำ1, jan/jul 2021.- PPGE - UNESC - ISSN 2317-2452

relacionadas à emoção. A mediação entre a afetividade e a cognição ocorre em decorrência de uma relação dialética e dentro de um processo unificado entre o agir, o perceber, o sentir, o pensar e o imaginar. Para compreender melhor como procede esse processo unificador, é importante que os conceitos de pensamento, sensação, percepção e imaginação adotados neste trabalho sejam elucidados.

O pensamento é gerado por nossos desejos e necessidades, nossos interesses e emoções. Só é possível obter uma visão completa do pensamento humano, a partir de uma compreensão da interação que ocorre entre o afeto e cognição, por meio do processo de comunicação. Nessa comunicação, a linguagem vai promover a construção de conhecimentos de si e do mundo.

A percepção é um processo onde são organizadas as informações obtidas por meio das sensações, essas se referem aos atributos dos estímulos, onde ocorre uma discriminação das características como peso, altura, tamanho, distância, etc.

Na composição humana, nos fios que tecem a vida, não é possível dissecar e ver em que esfera predomina a emoção e em qual predomina a cognição. Assepsia impossível.

O desenvolvimento da afetividade ocorre na vida do ser humano desde as suas primeiras vivências (percepções, sensações e emoções) e à medida que se estabelece um contanto com o outro e com o meio externo, essas relações são internalizadas de forma bastante singular por cada indivíduo.

\section{A AFETIVIDADE NA APRENDIZAGEM}

O indivíduo através de sua relação com o meio, promove novos conhecimentos e desenvolve diferentes dimensões do afeto, em suas diferentes formas de expressão e relações com as funções psíquicas. Assim a integração entre o desenvolvimento cognitivo e afetivo durante a construção do conhecimento contribui para a construção da subjetividade, e a manutenção do status da consciência que se constitui segundo Vygotsky (1993) em dois planos: primeiro no social (que representa uma combinação dialética entre o externo e o interno) e depois no psicológico (o interno - constituído a partir do social). De acordo com Bock (2001, p.99) "Vygotsky afirma que a natureza psicológica dos homens representa o agregado de relações sociais internalizadas que se torna para o indivíduo funções e formas de sua estrutura". A atividade de internalização, ou a subjetivação não é apenas cognitiva e 
Criar Educação, Criciúma, v. 10, nำ1, jan/jul 2021.- PPGE - UNESC - ISSN 2317-2452

intelectual, tendo também uma dimensão emocional.

$\mathrm{O}$ afeto e a cognição estão desde cedo íntima e dialeticamente relacionados, formando uma conexão entre a vida emocional e outros processos psicológicos, resultando no desenvolvimento da consciência de maneira geral. Para Bock (2001, p.105), "o processo cognitivo não existe descolado da emoção", pois a vida afetiva se constitui a partir das experiências dialeticamente construídas pelo homem em sua relação histórica com o social.

As ideias de Vygotsky discordavam com concepção da existência de uma dualidade entre a emoção e a cognição que divide o sujeito em duas dimensões: uma que se apodera dos comportamentos e a outra interessada em compreender os significados, motivações e volições humanas. De acordo com Arantes (2003, p. 18):

Quem separa desde o começo o pensamento do afeto fecha para sempre a possibilidade de explicar as causas do pensamento, porque uma análise determinista pressupõe descobrir seus motivos, as necessidades e interesses, os impulsos e tendências que regem o movimento do pensamento em um outro sentido. De igual modo, quem separa o pensamento do afeto, nega de antemão a possibilidade de estudar a influência inversa do pensamento no plano afetivo, volitivo da vida psíquica, porque uma análise determinista desta última inclui tanto atribuir ao pensamento um poder mágico capaz de fazer depender o comportamento humano única e exclusivamente de um sistema interno do indivíduo, como transformar o pensamento em um apêndice inútil do comportamento, em uma sombra sua desnecessária e impotente.

O afeto e a cognição atuam também como aspectos inseparáveis na aquisição do conhecimento. Para Vygotsky (1996), à medida que o homem toma conhecimento das sensações e experiências vividas, ocorre uma interação no seu sistema psicológico entre a afetividade e a cognição, conforme Rego (1995, p. 122), "segundo ele são os desejos, necessidades, emoções, motivações, interesses, impulsos e inclinações do indivíduo que dão origem ao pensamento e este por sua vez exerce influência sobre o aspecto afetivo volitivo".

O aprender exige do indivíduo uma constante interação entre as dimensões do afeto e da cognição e para que ocorra essa interação se faz necessário uma boa qualidade de relação entre os indivíduos envolvidos no processo ensino-aprendizagem. Uma não aprendizagem pode estar tanto dialeticamente ligada a fatores internos (próprios do indivíduo), quanto externos (mediações feitas entre a família-aluno, professor-aluno e família-professor), que por sua vez formam uma complexa rede de relacionamentos afetivos, resultando em implicações no desenvolvimento cognitivo do aluno. Toda 
Criar Educação, Criciúma, v. 10, n-1, jan/jul 2021.- PPGE - UNESC - ISSN 2317-2452

essa rede de relações pode refletir-se num sucesso ou insucesso de aprendizagem, que não tem ligações somente com os processos cognitivos.

\section{CONSIDERAÇÕES FINAIS}

Uma das ideias chave do presente trabalho é a de que o afeto e a cognição são elementos indissociáveis e indispensáveis no processo de aprendizagem. E que as ações humanas são ações sociais, cognitivas, discursivas e pragmáticas. Incluídas estão as formas de agir sobre o mundo: com o corpo, com os movimentos desse corpo, com olhar, com as expressões de afeto, amor e ódio, com as palavras, com os silêncios. O conhecimento das bases neuropsicológicas do processo de aprendizagem e do processo das emoções e afetividade torna-se importante para entendermos como o indivíduo internaliza e modifica seu comportamento ao longo do desenvolvimento normal.

A afetividade de forma geral está presente e influencia todas as nossas ações e decisões. É difícil conceber a vida de um ser humano sem que se considerem os afetos, uma vez que estes estão interligados a diferentes funções psíquicas e relacionam-se constantemente com estas, atribuindo ao homem esta posição diferenciada dos demais animais. Por essa relação dialética existente entre as funções psíquicas e o meio é que ocorre o aprendizado, que envolve tanto a cognição quanto a afetividade.

\section{REFERÊNCIAS}

ARANTES, V. A. (Org). Afetividade na Escola: Alternativas Teóricas e Práticas. São Paulo: Ed. Summus, 2003.

BAKHTIN, M. Marxismo e Filosofia da linguagem. São Paulo: Hucitec, 1992

BAQUERO R. Vygotsky e a Aprendizagem Escolar. Porto Alegre: Artes Médicas, 1998.

BEAR, M.. Neurociências: desvendando o sistema nervoso. 2a ed. Porto Alegre: Artmed, 2006.

BOCK, A. M. B. Psicologias: Uma introdução ao estudo da Psicologia. 13ª ed. São Paulo: Saraiva,1999. 
Criar Educação, Criciúma, v. 10, nำ1, jan/jul 2021.- PPGE - UNESC - ISSN 2317-2452

BOCK, A. M. B. Psicologia Sócio Histórica: Uma Perspectiva Crítica em Psicologia. São Paulo Ed. Cortez, 2001.

CODO, W. Educação: Carinho e Trabalho. Petrópolis RJ: Vozes, 2002

FONSECA, V. Educação Especial: Programa de Estimulação Precoce. $2^{\mathrm{a}}$ ed. Porto Alegre: Artes Médicas, 1995.

FURTADO, O. O psiquismo e a Subjetividade Social. IN BOCK, A. M. B. Psicologia Sócio Histórica: Uma Perspectiva Crítica em Psicologia. São Paulo Ed. Cortez, 2001.

FREITAS, M. A. Vygotsky e Baktin - Psicologia e Educação um Intertexto. $4^{\mathrm{a}}$ ed. São Paulo: Ática, 2000.

KIMURA, D. (1973). The assymetrics of the human brain. Scientific American, 4, 70-78.

KOHL, M. Vygotsky Aprendizado e Desenvolvimento: um Processo Sócio Histórico. 4a ed. São Paulo: Scipione, 2001.

KOHL, M.; SOUZA, D. T. R.; REGO, T. C. (Orgs.). Psicologia, educação e as temáticas da vida contemporânea. São Paulo, SP: Moderna, 2002.

LANE, S. T. M; SAWAIA, B. B. Novas veredas da Psicologia Social. São Paulo: Brasiliense, 1995

MESSER, C. Processos metacognitivos no ensino de conteúdos: Monitoramento cognitivo de professores em séries iniciais. (Dissertação de Mestrado). Pontifícia Universidade Católica do Rio Grande do Sul, Porto Alegre. 1995.

PIAGET, J. O Nascimento da Inteligência na Criança. Editora Zohar, Rio de Janeiro, 1970.

PIAGET, J. Psicologia e Pedagogia. 9a ed. Rio de Janeiro: Forense Universitária, 2003

REGO, T. C. Vygotsky: Uma Perspectiva Histórico Cultural. 9º ed. Rio de Janeiro: Vozes, 1995.

VIGOTSKI, L. S.; LEONTIEV, A. N.; LURIA, A. R. Linguagem, desenvolvimento e aprendizagem. $11^{\mathrm{a}}$ ed. São Paulo: Ícone, 2010.

VYGOTSKY, L. S. Teoria e método em psicologia. São Paulo: Martins Fontes, 1996

VYGOTSKY, L. S. A formação social da mente. São Paulo: Martins Fontes, 1991. 
